\title{
Generation of CRISPR-cas9 construct for knockout of genes encoding chromatin- associated proteins
}

\author{
Mumtaz Aarif Wani ${ }^{1}$ and Aijaz Ahmad Ganaie $2^{2^{*}}$
}

\begin{abstract}
Background: Eukaryotic genomes have a multiscale three-dimensional organization varying from nucleosomes, loops, topologically associating domains, and chromosome territories. Chromatin, DNA wrapped around histone proteins, helps in packaging long DNA within tiny nuclear spaces. We used CRISPR-cas9, which is a system of single-protein and single-guide RNAs for genome engineering and also is simple and target specific.

Method: Two major protein families involved in maintaining and regulating structure and dynamics of chromatin are trithorax group (TrxG) and polycomb group (PcG) proteins. This study was undertaken to generate knockout cell lines of some TrxG and PCG proteins using the CRISPR-based approach in order to study their role in higher order chromatin organization.

Results: From TrxG, ISWI and Acf were selected, and from PcG, Pc and Psc were selected. Three pAc-sgRNA-Cas9puro-vector constructs for ISWI gene, one pAc-sgRNA-cas9-puro-vector construct for Pc, gene and two pAc-sgRNAcas9-puro-vector constructs for each of the Acf and Psc gene were generated. These constructs were confirmed by PCR and sequencing.
\end{abstract}

Conclusion: In the future, these constructs will be used to study the role of their respective target genes in chromatin organization.

Keywords: Trithorax group proteins, Polycomb group proteins, CRISPR-cas9

\section{Introduction}

Chromatin is a complex structure consisting of DNA, proteins, and RNA. Chromatin is packaged into small nuclear space in the cell, but at the same time chromatin is accessible to various transcription factors. This dynamic nature of chromatin is maintained by various proteins and protein complexes. The structural proteins, called histones, help in the DNA assembly. The core histones, namely $\mathrm{H} 2 \mathrm{~A}, \mathrm{H} 2 \mathrm{~B}, \mathrm{H} 3$, and $\mathrm{H} 4$, form the nucleosome, which is the basic unit of chromatin organization. The nucleosome consists of an octamer of core histones made of a pair of each core histone and a DNA fragment of $146 \mathrm{bp}$ wrapped around the octamer core. This forms the "beads on a string" structure of

\footnotetext{
* Correspondence: sahilaejaz@gmail.com

${ }^{2}$ Environmental Biotechnology Lab, Deptt. of P.G Studies and Research in Biological sciences, R. D. University, Jabalpur 482001, India

Full list of author information is available at the end of the article
}

chromatin, then nucleosomal chromatin to a compact structure called 30-nm fiber chromatin (heterochromatin). The $30-\mathrm{nm}$ fiber is packaged to a higher level into the metaphase chromosome. Chromatin-associated proteins are of two counteracting groups, trithorax group (TrxG) and polycomb group (PcG) that maintain the cellular memory. TrxG is of critical importance in the senescence, DNA damage, epigenetic regulation of the cell cycle, and stem cell biology (Ingham 1998). Trithorax chromatin regulators are evolutionarily conserved proteins and can be divided into three classes on the basis of their molecular function. One class, methylate histone tails, contains a SET domain. The second class, ATP-dependent chromatin remodeling factors, includes proteins that can read the histone methylation marks that are laid down by the SET domain proteins. The third class can directly bind to specific DNA sequences and includes TrxG proteins comprised of 


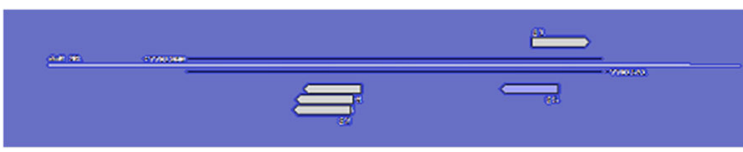

Fig. 1 Picture showing position of guide sequences for the selected sequence of a gene

some histone modifiers and chromatin remodelers, as well as proteins that are not categorized within the first two classes. Thus, most of the Trx proteins perform their functions as a part of their large multiprotein complexes that are histone modifiers or nucleosome remodelers, to regulate gene expression. PcG implement transcription silencing in higher eukaryotes by forming chromatin-modifying complexes. Two main families of complexes, called polycomb repressive complex (PRC) 1 and PRC2, are targeted to repress DNA regions. We used CRISPR-cas9 technology to generate pAc-sgRNAcas9puro-vector knockout constructs for some proteins of these two groups (TrxG and PcG) to study their function. Clustered regularly interspaced short palindromic repeats [CRISPR] are DNA sequences found in prokaryotic genomes (Grissa et al. 2007). Each repeat is followed by a "spacer DNA," which is adopted from a previous infection by a phage or plasmid (Marraffini and Sontheimer 2010). Simply, CRISPR-Cas9 is an immune system in prokaryotes and provides a form of acquired immunity against phages and plasmids. CRISPR-associated genes [Cas genes] are a set of genes that are closely associated with CRISPR. Bacteria which are able to survive a viral infection fragmentize the viral DNA and then integrate few of these fragments into their CRISPR loci and also pass on this genetic information generation to generation. Whenever in the future the same bacteria or its progeny is infected by the same viral strain or another viral strain which shares the same genetic information which the bacteria has integrated into its CRISPR locus are able to survive the infection with the help of CRISPR activation, the RNAs transcribed from CRISPR loci called CRISPR RNA [crRNA] (Pennisi 2013) or guide RNA. RNA makes a stable complex with Cas protein and navigates and binds the specific target in viral DNA and makes a double-strand break, hence degrading the viral DNA and, in this way, escaping viral invasion.
Streptococcus pyogenes has a CRISPR system and a singlecas gene called cas9 that is required for the function of this CRISPR system in the bacterium. Cas9 is a fascinating enzyme. Cas9 has the ability to interact with DNA and generate a double-strand break [DSB] at sequences that match the guide RNA sequences. The guide RNA base pairs with protospacer in viral DNA to allow cas9 enzyme to cause a specific double-strand break. The guide RNA also base pairs with another RNA sequence called tracrRNA to form a structure that recruits the cas9 enzyme. Therefore, two RNAs, guide RNA and tracrRNA, and cas9 enzyme are required to form a complex that recognizes the viral DNA and degrades it. In 2012, Jinek et.al linked together guide RNA and tracrRNA molecules to form a single-guide RNA [sgRNA], to generate a system of single-protein and single-guide RNA for genome engineering. This new genome engineering technology is simply called CRISPR-cas9 technology. This technique is used to generate knockout cell lines which in turn provide the information regarding the function of the same gene (Jinek et al. 2012).

CRISPR/Cas9 systems have been successfully used for precise genome editing in mouse embryonic stem cells (ESCs) and targeted biallelic mutagenesis in F0 zebrafish (Jao et al. 2013; Wang et al. 2013; Yang et al. 2013). Recently, CRISPR-Cas9 systems have been used to efficiently edit the genome of adult mice in vivo in the liver and muscle (Long et al. 2014; Xue et al. 2014; Yin et al. 2014). The RNA-guided Cas9 endonuclease induces sequence-specific DNA double-strand breaks (DSBs) that are repaired mostly by the classical and alternative nonhomologous end-joining pathways (c-NHEJ or AEJ) or by homology-directed repair (HDR) (Boboila et al. 2012). This study was carried out to generate the knockout cell lines of chromatin-associated proteins, viz, polycomb and trithorax. The constructs for some of these genes were successfully generated which will be used in the future to generate the knockout cell lines of the same. This study will provide insight into the mechanism how these proteins are responsible for the chromatin structure and function.

This study was carried out to design and synthesize guide sequences for TrxG (ISWI and Acf) and PcG (Pc and Psc) proteins and to generate CRISPR-cas9 constructs to knockout TrxG (ISWI and Acf) and PcG (Pc and Psc) genes.

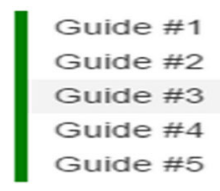

score
95
94
92
85
81

Fig. 2 Guide sequences with their scores

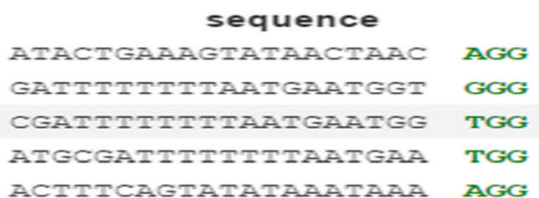

AGG 
Table 1 Guide sequences of genes under study

\begin{tabular}{|c|c|c|c|c|}
\hline S. no. & Name of the target gene & No. of guides & Name of guides & Guide sequence $5^{\prime}$ to $3^{\prime}$ \\
\hline 01. & ISWI & 03 & $\begin{array}{l}\text { ISWI19, ISWI20, ISWI21, ISWI22 } \\
\text { and ISWI23 }\end{array}$ & $\begin{array}{l}\text { TTCGACGGCAGCTGTATCTGTT, TTCGGGTCTACCCTTAGGCTTCGT, } \\
\text { TCGATATCTCCGTCTGCTITAGC, TTCGCTITCACCGGATGAACTGG, } \\
\text { TTCGTAAGAGTCCCACGAAGCCTA }\end{array}$ \\
\hline 02. & Acf & 02 & Acf10 and Acf11 & $\begin{array}{l}\text { TTCGCCTTCGGGCACCCGTCCTTC, TTCG } \\
\text { GGTGTTGACCGCCGACTGTT }\end{array}$ \\
\hline 03. & Pc & 02 & $P C 1, P c 2$ & $\begin{array}{l}\text { TTCGGCCGCGTACACTAGATCGAC, TTCG } \\
\text { TCCAGTCGATCTAGTGTACG }\end{array}$ \\
\hline 04. & Psc & 02 & Psc 8 and Psc9 & $\begin{array}{l}\text { TTCGGGCTGTATTGCTITCGATTC, TTCG } \\
\text { GACAACGGCAACGAATAAGG }\end{array}$ \\
\hline
\end{tabular}

\section{Methodology}

\section{Designing guide oligos}

Select 23-250NT sequence of your desired gene and paste it in a web tool called crispr.mit.edu. Download the guide sequences and choose the guides on the basis of score of guides (Figs. 1 and 2). If target sequence does not begin with $\mathrm{G}$, add $\mathrm{G}$ to its $5^{\prime}$ end to allow transcription from the U6 promoter. For the forward oligonucleotide, add TTC to the $5^{\prime}$ end of the target sequence. For the reverse oligonucleotide, reverse complement the target sequence (including an additional G nucleotide), and add AAC to the $5^{\prime}$ end. Synthesize the oligonucleotides. Oligos were synthesized as shown in Table 1.

\section{Annealing of oligos}

The forward and reverse oligos were annealed using PCR machine as follows: Mix $10 \mu \mathrm{l}$ of $2 \mathrm{x}$ annealing buffer (20 $\mathrm{mM}$ Tris, $2 \mathrm{mM}$ EDTA, $100 \mathrm{mM} \mathrm{NaCl}, \mathrm{pH} 8.0$ ) with $5 \mu \mathrm{l}$ each of $100 \mathrm{uM}$ forward and reverse oligos.

\section{Annealing program}

The oligos are annealed as shown in Table 2. Incubate for 30 min at $37^{\circ} \mathrm{C}$. Dilute $10 \mathrm{x}$ in $\mathrm{ddH}_{2} \mathrm{O}$.

\section{Phosphorylation of annealed oligos}

After annealing, the oligos were phosphorylated using annealed oligos $(1 \mu \mathrm{l}, 10 \mu \mathrm{M})$, Roche T4 DNA ligase buffer $(1 \mu \mathrm{l}, 1 \mathrm{x}$, contains ATP), T4 polynucleotide kinase

Table 2 Annealing program

\begin{tabular}{|c|c|}
\hline $98^{\circ} \mathrm{C}$ & $1 \mathrm{~min}$ \\
\hline $98-88^{\circ} \mathrm{C}$ & $5 \mathrm{~s}$, decrease $0.1^{\circ} \mathrm{C} /$ cycle $\times 99$ cycles \\
\hline $88-78^{\circ} \mathrm{C}$ & $10 \mathrm{~s}$, decrease $0.1^{\circ} \mathrm{C} /$ cycle $\times 99$ cycles + \\
\hline $78-68^{\circ} \mathrm{C}$ & 10s, decrease $0.1^{\circ} \mathrm{C} /$ cycle $\times 99$ cycles \\
\hline $68-58^{\circ} \mathrm{C}$ & 10s, decrease $0.1^{\circ} \mathrm{C} /$ cycle $\times 99$ cycles \\
\hline $58-48^{\circ} \mathrm{C}$ & $10 \mathrm{~s}$, decrease $0.1^{\circ} \mathrm{C} /$ cycle $\times 99$ cycles \\
\hline $48-38^{\circ} \mathrm{C}$ & $10 \mathrm{~s}$, decrease $0.1^{\circ} \mathrm{C} /$ cycle $\times 99$ cycles \\
\hline $38-18^{\circ} \mathrm{C}$ & $10 \mathrm{~s}$, decrease $0.1^{\circ} \mathrm{C} /$ cycle $\times 99$ cycles \\
\hline $18^{\circ} \mathrm{C}$ & Forever \\
\hline
\end{tabular}

$(1 \mu \mathrm{l}, 1 \mathrm{U}), \mathrm{ddH}_{2} \mathrm{O}(7 \mu \mathrm{l})$ to make the final volume $10 \mu \mathrm{l}$ and incubate at $37^{\circ} \mathrm{C}$ for $10 \mathrm{~min}$.

\section{Digestion of pAc-sgRNA-cas9-puro-vector}

Meanwhile, $2 \mu \mathrm{g}$ pAc-sgRNA-Cas9 vector (300 ng, $12 \mu \mathrm{l}$ ) was digested for $1 \mathrm{~h}$ at $37^{\circ} \mathrm{C}$ using NEB buffer $4(1 \mathrm{x}$, $5 \mu \mathrm{l})$, BspQ1 (NEB, $2 \mu \mathrm{l})$, and $\mathrm{ddH}_{2} \mathrm{O}(31 \mu \mathrm{l})$ to make the final volume $50 \mu \mathrm{l}$. Run the digested vector on agarose gel and purify the digested vector using a kit by the manufacturer's protocol.

\section{Ligation of digested vector pAc-sgRNA-Cas9-puro and phosphorylated oligos}

The ligation was performed using pAc-sgRNA-Cas9puro-vector $(2 \mu \mathrm{l}), 10 \mathrm{x}$ diluted oligos $(2 \mu \mathrm{l})$, Roche T4 DNA ligase buffer $(1 \mu \mathrm{l})$, T4 DNA ligase $(1 \mu \mathrm{l})$, and $\mathrm{ddH}_{2} \mathrm{O}(4 \mu \mathrm{l})$ to make the final volume $10 \mu \mathrm{l}$ and incubate at $18{ }^{\circ} \mathrm{C}$ for $2 \mathrm{~h}$.

\section{Transformation}

Transform $2 \mu \mathrm{l}$ of ligated vector (with desired oligos) to a $50 \mu \mathrm{l}$ aliquot of chemically competent DH5- $\alpha$ cells by:

- Incubate $20 \mathrm{~min}$ on ice with plasmid.

- Heat shock for $30 \mathrm{~s}$ at $42{ }^{\circ} \mathrm{C}$.

- Cool for $2 \mathrm{~min}$ on ice.

- Use LB-ampicillin/carbenicillin plates $(100 \mu \mathrm{g} / \mathrm{ml})$.

- Incubate at $37^{\circ} \mathrm{C}$ overnight.

Table 3 CRISPR-CAS9 constructs to knockout TrxG and PcG genes+

\begin{tabular}{llllll}
\hline $\begin{array}{l}\text { S. } \\
\text { no }\end{array}$ & $\begin{array}{l}\text { Name of the } \\
\text { target gene }\end{array}$ & $\begin{array}{l}\text { No. of } \\
\text { guides }\end{array}$ & $\begin{array}{l}\text { Name of } \\
\text { guides }\end{array}$ & $\begin{array}{l}\text { Conformation } \\
\text { by PCR }\end{array}$ & $\begin{array}{l}\text { Conformation } \\
\text { by sequencing }\end{array}$ \\
\hline 1 & ISWI & 03 & ISWI21, & YES & YES \\
& & & Y2, & YES & YES \\
& & & 23 & YES & YES \\
2 & Acf & 02 & Acf 10 & YES & YES \\
& & & Acf11 & YES & YES \\
3 & PC & 02 & PC2 & YES & YES \\
4 & PSC & 02 & PSC8 & YES & YES \\
& & & PSC9 & YES & YES \\
\hline
\end{tabular}




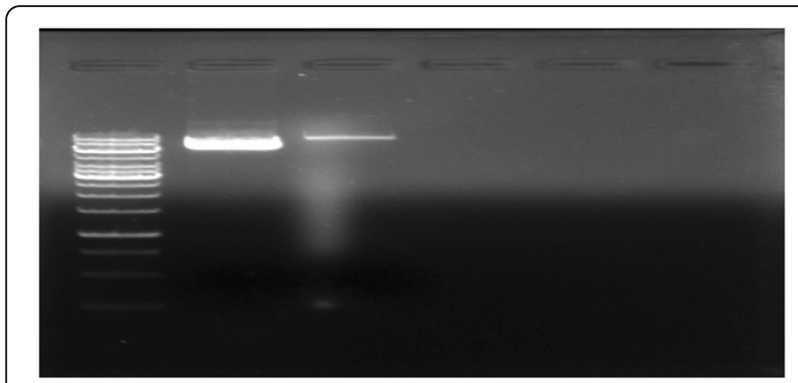

Fig. $31 \%$ agarose gel of undigested and digested pAc vector

- The next day, three colonies for each clone were randomly selected and inoculated in $5 \mathrm{ml}$ LB broth containing ampicillin $1 \mu \mathrm{g} / \mathrm{ml}$. The tubes were kept in a shaking incubator at $37^{\circ} \mathrm{C}$ overnight.

- Isolation of plasmids was done using Qiagenmini prep kit.

- The integrity of the plasmids was checked on agarose gel.

\section{Confirmation of positive constructs by PCR and sequencing}

Confirmation of positive constructs was done by PCR using buffer $(1 \mathrm{x}, 5 \mu \mathrm{l})$, dNTPs $(1.5 \mathrm{mM}, 5 \mu \mathrm{l})$, Forward primer (U6F, $0.25 \mu \mathrm{M}, 1.25 \mu \mathrm{l}$ ), Reverse primer $(0.25 \mu \mathrm{M}, 1.2 \mu \mathrm{l})$, Template (50 ng, $1 \mu \mathrm{l})$, Taq. Pol. (0.05, $0.1 \mu \mathrm{l})$, and MQ $(36.4 \mu \mathrm{l})$ to make the final volume $50 \mu \mathrm{l}$. The PCR program followed was hot start $\left(95^{\circ} \mathrm{C}\right.$, $5 \mathrm{~min})$, denaturation $\left(95^{\circ} \mathrm{C}, 30 \mathrm{~s}\right)$, annealing $\left(56^{\circ} \mathrm{C}, 30 \mathrm{~s}\right)$, extension $\left(72{ }^{\circ} \mathrm{C}, 25 \mathrm{~s}\right)$, and last extension $\left(72^{\circ} \mathrm{C}, 7 \mathrm{~min}\right)$.

The positive pAc-sgRNA-Cas9-puro-vector constructs were sent to Scigenom (Kochi, India) for sequencing. The sequencing was checked by alignment using Emboss needle web tool.

\section{Results and discussion}

Eight CRISPR-CAS9 constructs to knockout TrxG and PcG genes were successfully generated as shown in Table 3.

\section{Generation of pAc-sgRNA-Cas9-puro-vector TrxG (ISWI and Acf) constructs}

In order to generate CRISPR-based knockout cell lines of ISWI, the pAc vector was digested with BspQ1, as shown in Fig. 3. The digested vector and the annealed, phosphorylated oligos were ligated. We first ligated five phosphorylated guides of ISWI, i.e., ISWI19, ISWI20, ISWI21, ISWI22, and ISWI23, with the digested vector. Next, transformation of the same was performed in DH5-alpha competent cells. After transformation, DH5-alpha cells were grown on LB-ampicillin agar plates. We got a good number of colonies only for ISWI19, 21, 22, and 23. Three colonies from each plate were randomly selected and inoculated in $5 \mathrm{ml} \mathrm{LB}$-ampicillin broth. The tubes were kept at $37^{\circ} \mathrm{C}$ in a shaking incubator overnight. The next day, recombinant plasmids were isolated using miniprep kit. On running the isolated recombinant plasmids on 1\% agarose gel, only ISWI21, 22, and 23 showed positive clones as shown in Fig. 4. The pAc-sgRNA-cas9-puro-vector was ran as the control. The confirmation of positive clones was further confirmed by PCR and sequencing sequentially. For the PCR confirmation, the U6F and the complementary oligo of guide sequences were used as primers and the PCR products were run on 1\% agarose gel, as shown in Fig. 5. For the confirmation by sequencing U6F primer was used, the sequencing results are shown in Fig. $6 \mathrm{a}-\mathrm{c}$.

For the generation of knockouts of TrxG gene Acf, two different guide sequences were selected for Acf. These two guide sequences were annealed with their complementary guide sequences and phosphorylated. Meanwhile, the pAc-sgRNA-Cas9-puro-vector was

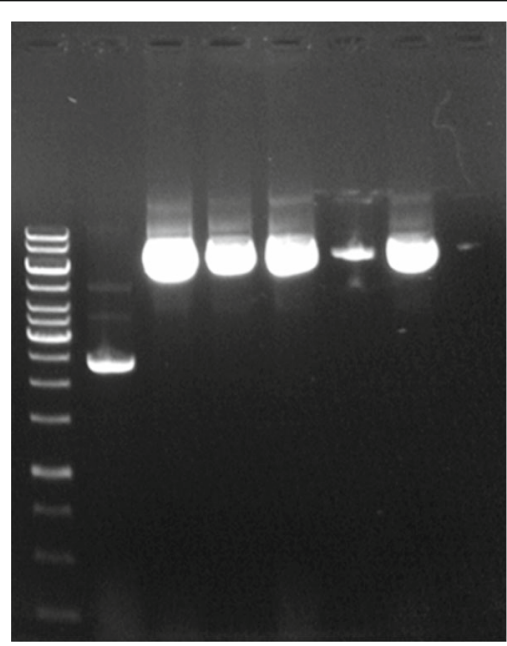

Lane L: $1 \mathrm{~kb}$ ladder; Lanes: 1, 2, 3, and 4:

ISWI19, ISWI21, ISWI22 and ISWI 23 respt.

Lanes: 5 and 6: pAc-sgRNA-cas9-puro-vector

Fig. 4 1\% agarose gel of recombinant plasmids of ISWI guide sequences 


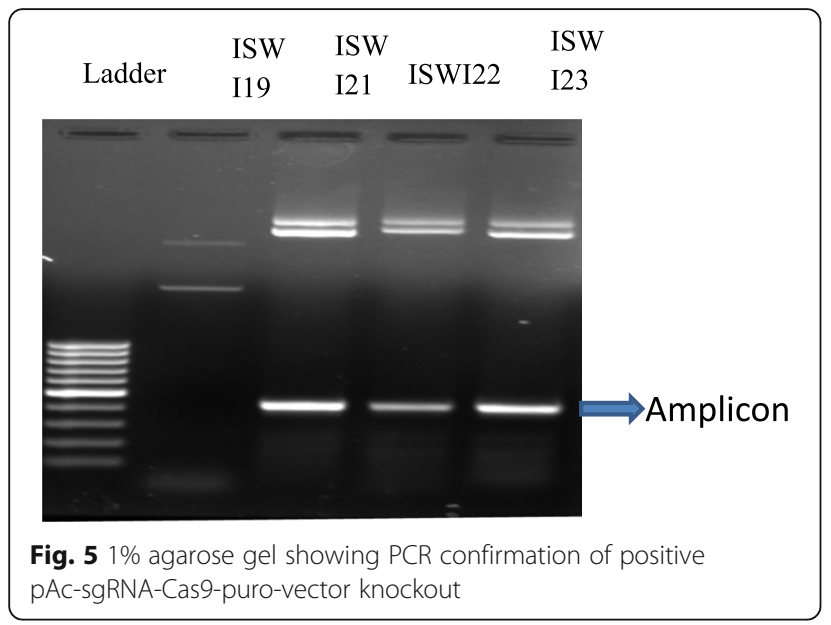

\section{Sequencing report of ISWI constructs}

a designed with BspQ1 restriction enzyme as mentioned in the materials and methods, purified and ligated with the guide oligos. Transformation of the ligated plasmids was performed in DH5-alpha competent cells and plated on LB-ampcillin agar plates. The next day, single colonies, two from each, were inoculated in $\mathrm{LB}$ broth and were grown overnight at $37^{\circ} \mathrm{C}$ in a shaking incubator. Recombinant plasmids as shown in Fig. $7 \mathrm{a}$, were isolated and the integrity of plasmids was checked on 1\% agarose gel. As evident from Fig. $7 \mathrm{a}$, the impurities were found in the plasmids and the same experiment was repeated as shown in Fig. 7b. The Acf10 and Acf11 constructs were confirmed for the presence of insert by PCR and sequencing. The PCR was performed using U6F primer and the complementary sequence of each oligo. The PCR
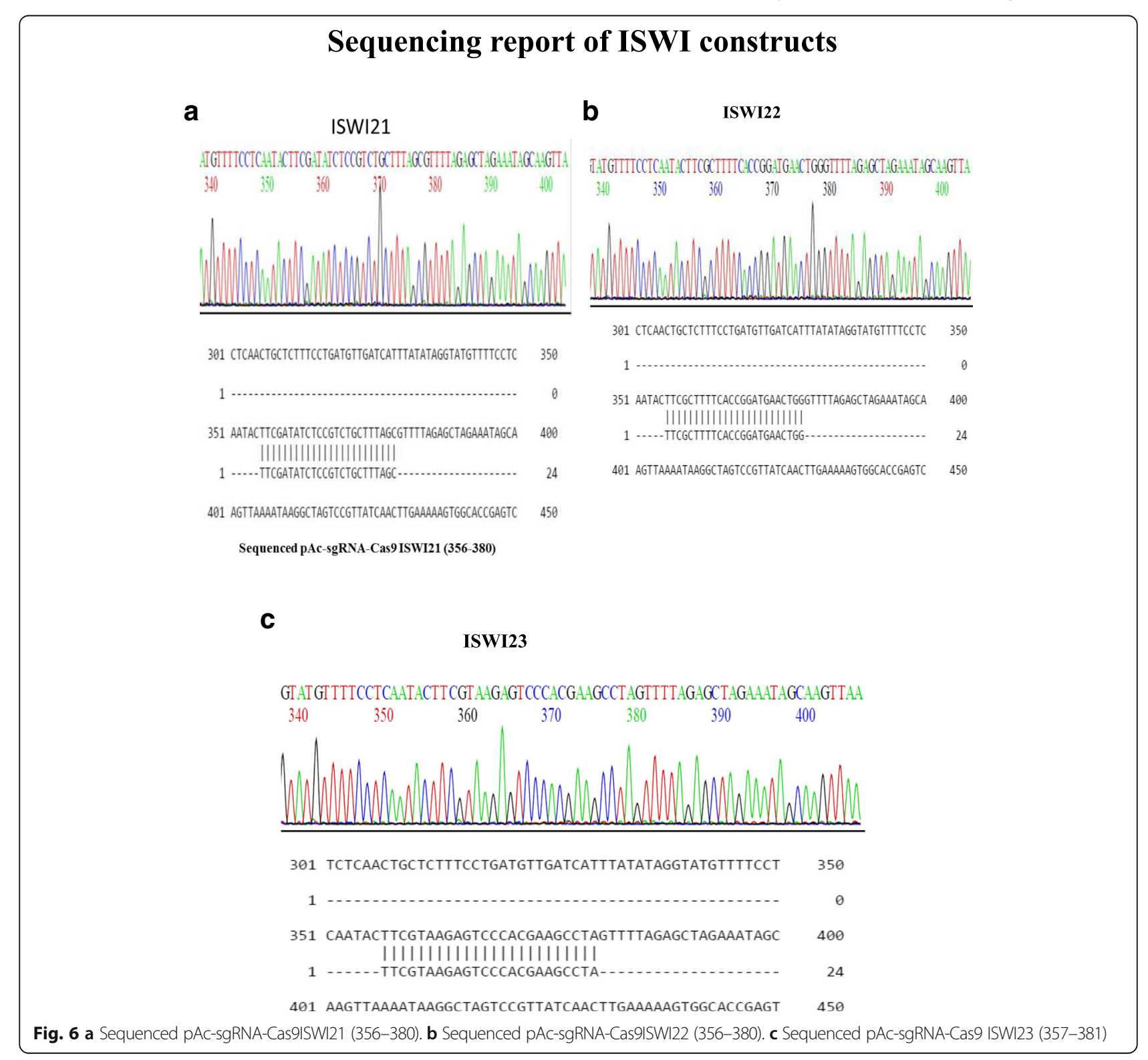


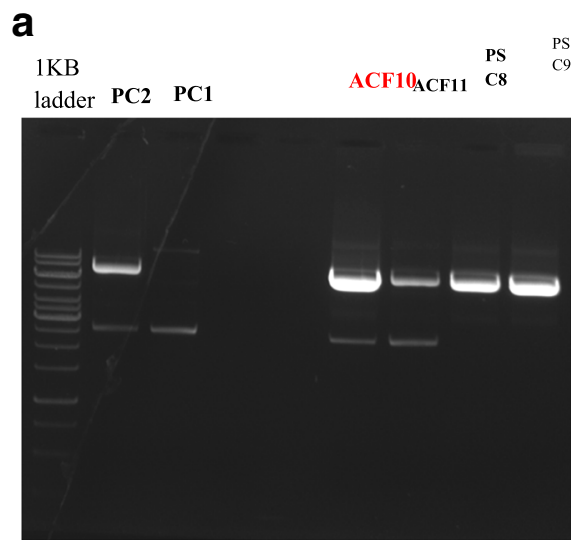

b

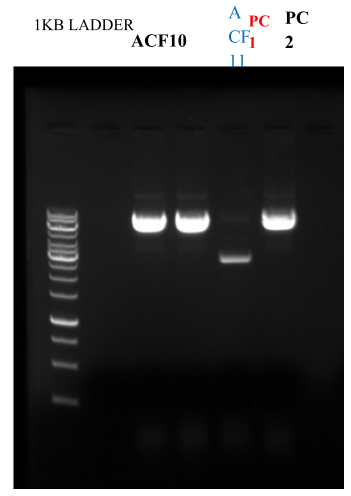

Fig. $\mathbf{7}$ a and $\mathbf{b} 1 \%$ agarose gel of positive pAc-sgRNA-Cas9-puro-vector constructs for Pc, Acf and Psc genes

products were run on $1 \%$ agarose gel keeping pAcsgRNA-cas9-puro-vector as the negative control as shown in Fig. 8a. The size of the PCR fragment was found almost $491 \mathrm{bp}$ as expected in each case. Further confirmation of the recombinants was performed by sequencing using U6F primer as shown in Fig. 9b, c.

\section{Generation of CRISPR-Cas9 constructs for polycomb group [PcG] proteins [Pc and Psc]}

For the generation of knockouts of PcG genes, Pc and Psc, and one and two different guide sequences, respectively, were selected for each gene. These guide sequences were annealed with their complementary guide sequences and phosphorylated as mentioned in the materials and methods. Meanwhile, the pAc-sgRNA-Cas9puro-vector was digested with BspQ1, purified and ligated with the guide oligos. Transformation of the ligated plasmids was performed in DH5-alpha competent cells and plated on LB-ampcillin agar plates. The next day, single colonies, two from each, were inoculated in $\mathrm{LB}$ broth and were grown overnight at $37^{\circ} \mathrm{C}$ in a shaking incubator. Recombinant plasmids as shown in Fig. 7a were isolated, and the integrity of plasmids was checked on $1 \%$ agarose. As evident from Fig. 7a, the impurities were found in the plasmids except Psc8 and Psc9.The same experiment was repeated for the generation of Pc1 and Pc2 constructs. The recombinant plasmids of these genes were run on $1 \%$ agarose gel, as shown in Fig. 7b. The impurity was still found in the case of Pc1. The Pc2, Psc8, and Psc9 constructs were confirmed for the presence of insert sequentially by PCR and sequencing. The PCR was performed using U6F primer and the complementary sequence of each oligo. The PCR products were ran on $1 \%$ agarose gel keeping pAc-sgRNA-cas9-puro-vector as the negative control as shown in Fig. 8a, b. The size of the PCR fragment was found almost $491 \mathrm{bp}$ as expected in each case. Further confirmation of the recombinants was performed by sequencing using U6F primer as shown in Fig. 9a, d, e.

\section{Discussion}

The CRISPR/Cas9 system is proven to be a powerful yet simple tool to manipulate the genome for the generation of genetically modified animals. In this study, we report the successful generation of eight CRISPR-cas9 constructs to knockout TrxG and PcG. We synthesized five guide sequences ISWI19, ISWI20, ISWI21, ISWI22, and ISWI23 for TrxG protein, ISWI. Among the five guides sequences, only three ISWI21, ISWI22, and ISWI23 successfully integrated into pAc-sgRNA-cas9-puro-vector to form three CRISPR-cas9 constructs for ISWI gene.

Chromatin-associated proteins are of two counteracting groups, trithorax group (TrxG) and polycomb group (PcG), that maintain the cellular memory. TrxG is of critical importance in the senescence, DNA damage, epigenetic regulation of the cell cycle, and stem cell biology. Trithorax chromatin regulators are evolutionarily conserved proteins and can be divided into three classes on the basis of their molecular function. One class is methylate histone tails, and it contains SET domain. The second class, ATP-dependent chromatin remodeling factors, includes proteins that can read the histone methylation marks that are laid down by the SET domain proteins. The third class can directly bind to specific DNA sequences and includes TrxG proteins comprised of some histone modifiers and chromatin remodelers, as well as proteins that are not categorized within the first two classes. Thus, most of the Trx proteins perform their functions as a part of their large multiprotein complexes that are histone modifiers or nucleosome remodelers, to regulate gene expression. PcG implement transcription silencing in higher eukaryotes by forming chromatin-modifying complexes. Two main families of complexes, called polycomb repressive complex (PRC) 1 and PRC2, are targeted to repress DNA 


\section{a}

$\begin{array}{lllll}\begin{array}{l}1 \mathrm{~kb} \\ \text { ladder }\end{array} & \begin{array}{l}\text { Control } \\ \text { (dcas) }\end{array} & \text { PC2 } & \text { ACF } & \begin{array}{l}\text { ACF } \\ 11\end{array} \\ & & 10 & \end{array}$

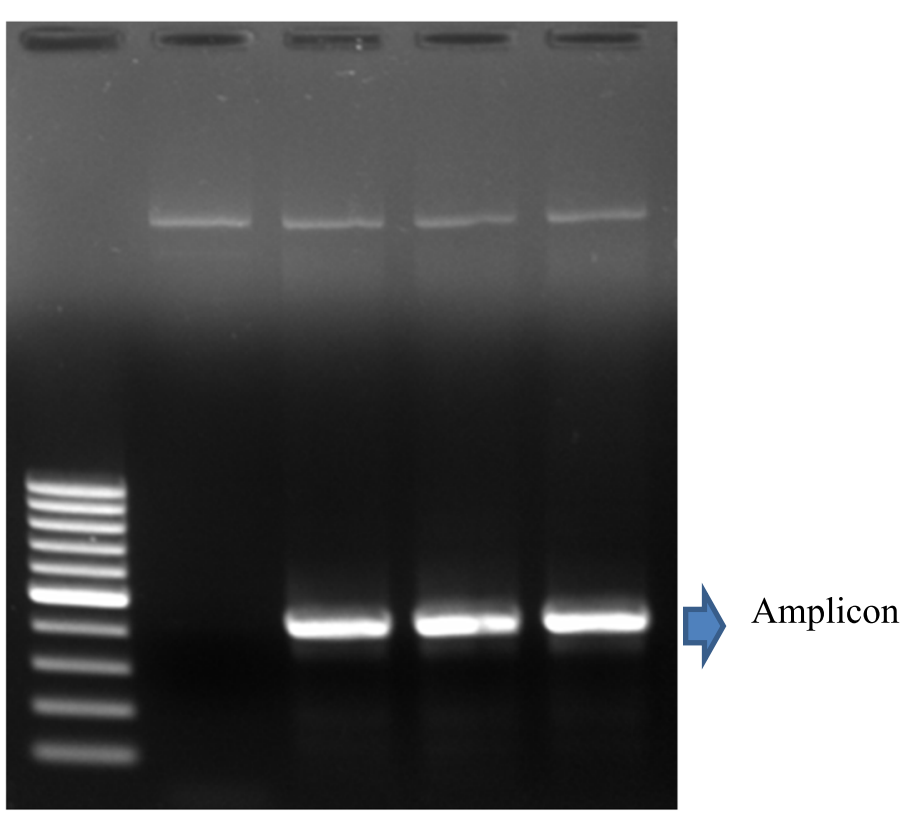

b
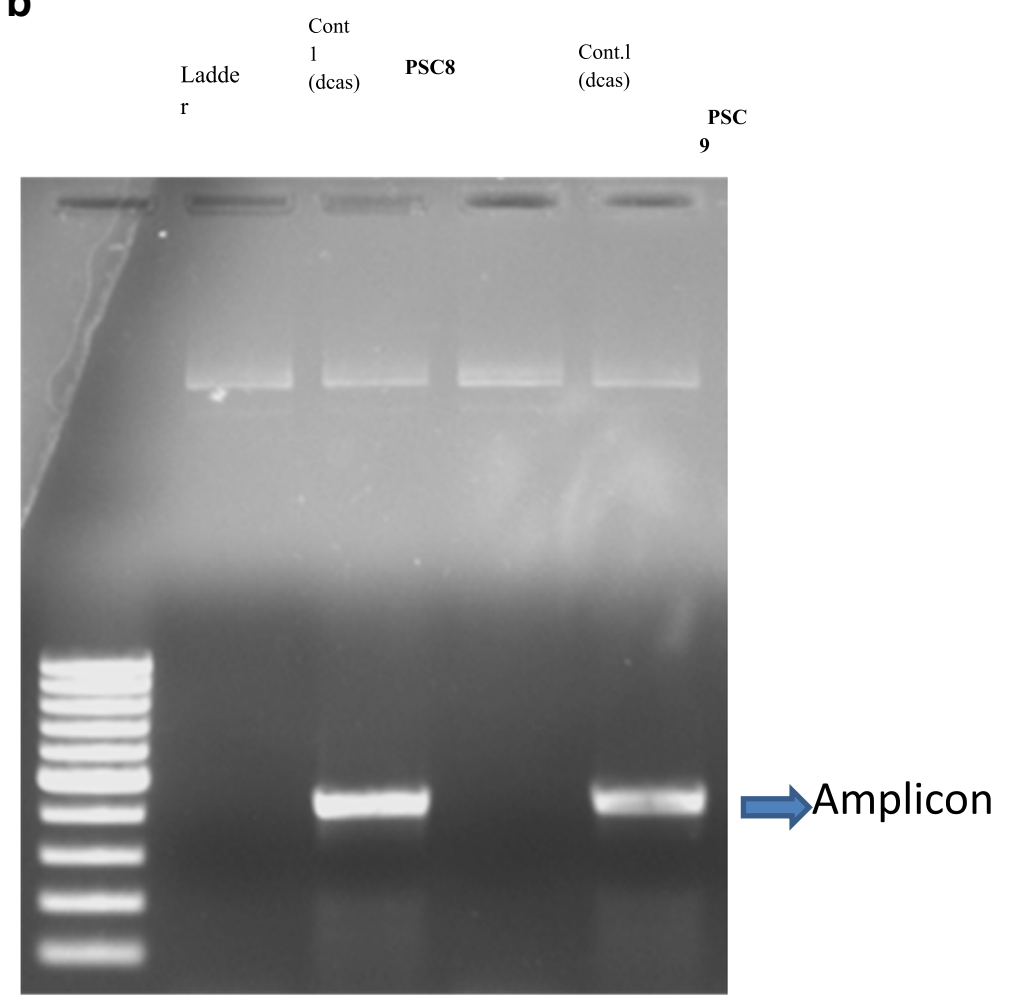

Fig. 8 a 1\% agarose gel showing PCR confirmation of pAc-sgRNA-Cas9-puro-vector-positive construct for PC and ACF genes. b 1\% agarose gel showing PCR confirmation of positive PAc-sgRNA-Cas9-puro-vector construct for PSC gene 


\section{a}

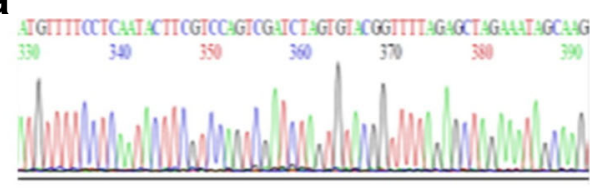

3 IC1 TCTITCCTGATGTTGATCATTTATATAGGTATGITITCCTCAATACTTCG 35e

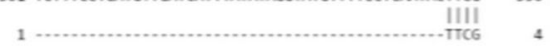

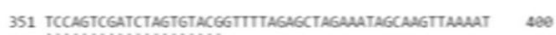

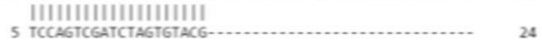

401 AMGGCTAGTCCGTTATCAACTTGAAMAGTGGCACCGAGTCGGTGCTITT 450

Sequenced P Ac-soRNA-Caso PC2 sequencing of $P C$

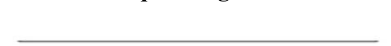

b

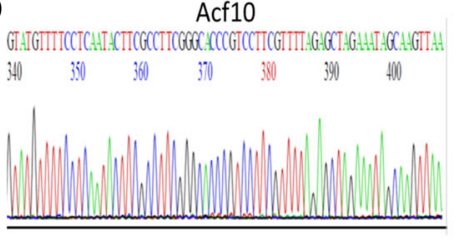

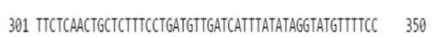

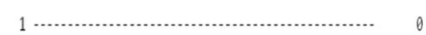

351 TCAATACTTCGCCTTGGGGACCCGTCCTTCGTtTAGGGGTAGAATAG 400

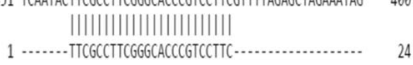

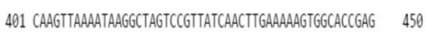

C Acf11

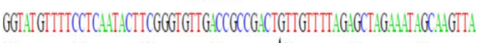

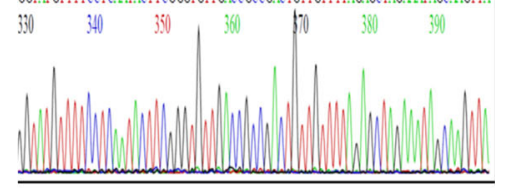

301 gCtctitcctgatgitgatcattiatataggtatgitticctcaAtact 350

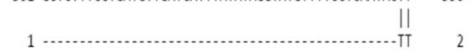

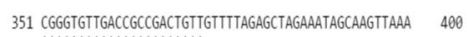
|||||||||||||||||||||||||||

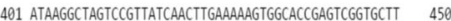

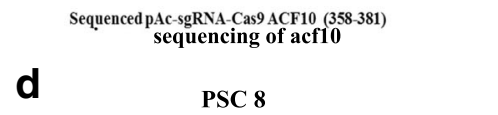

Sequenced pAc-sgRNA-Cas9 ACF11 (349-372)

Sequencing of Acf11

e

PSC 9

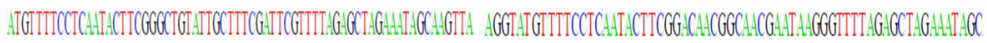
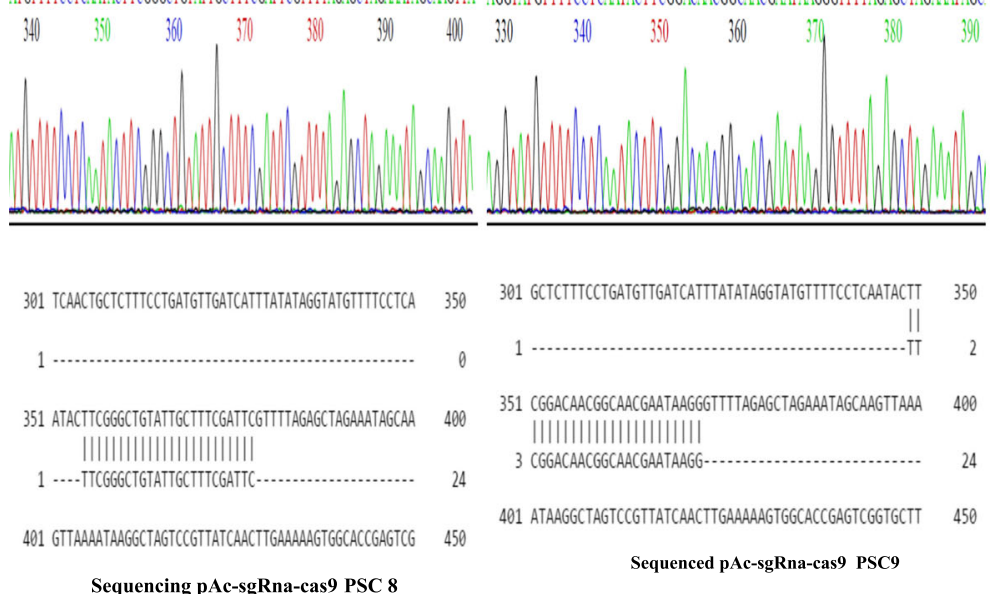

Fig. 9 a Sequencing of PC. b sequencing of acf10. c Sequencing of Acf11. d Sequencing pAc-sgRna-cas9 PSC 8. e Sequenced pAc-sgRna-cas9 PSC9

regions. We used CRISPR-cas9 technology to generate pAc-sgRNAcas9-puro-vector knockout constructs for some of the proteins of these two groups (TrxG and PcG) to study their function. In 2012, Martin Jinek et al. linked together guide RNA and tracrRNA molecules to form a single-guide RNA [sgRNA] to generate a system of single-protein and single-guide RNA for genome engineering. This new genome engineering technology is 
simply called CRISPR-cas9 technology. This technique is used to generate knockout cell lines which in turn provide the information regarding the function of the same gene.

The first response of CRISPR-Cas system is to capture viral DNA and select spacers from it to insert them into CRISPR locus (Tyson and Banfield 2008). Cas1 and Cas2 are found in all three CRISPR-Cas immune systems that indicate they are involved in spacer adaptation. This hypothesis was confirmed by mutation studies (Aliyari and Ding 2009; Dugar et al. 2013; Hatoum-Aslan et al. 2011). There are multiple Cas1 proteins with diverse amino acid sequences, but similar crystal structures. All purified Cas1 proteins are metal-dependent nucleases/integrases and show sequence independent binding to DNA (Wiedenheft et al. 2012).After analysis of repeat-spacer array, it was found that the spacers which were selected from phage genomes were not randomly selected, but only those regions called protospacers are selected for adaptation in the CRISPR locus. These protospacers lie upstream adjacent to short[3-5 bp] DNA sequences called protospacer-adjacent motifs[PAMs]. Analysis of CRISPR-Cas systems showed that PAMs are important for type I and type II systems only (Horvath et al. 2008; Deveau et al. 2008). Different CRISPR-Cas systems show conservation of the PAM sequences they recognize. New spacers are preferentially added adjacent to leader sequence in a directional manner (Shah et al. 2009). A single long primary transcript is transcribed from the promoter in the leader sequence. CRISPR RNAs [crRNAs] are formed from this single transcript by cleavage inside the repeat sequence. The mechanism of production of crRNAs is different in the three CRISPR systems.

\section{Conclusion}

We synthesized five guide sequences ISWI19, ISWI20, ISWI21, ISWI22, and ISWI23 for TrxG protein, ISWI. Among the five guides sequences only three ISWI21, ISWI22, and ISWI23 successfully integrated into pAcsgRNA-cas9-puro-vector to form three CRISPR-cas9 constructs for ISWI gene. Two guide sequences, Acf10 and Acf11, were synthesized for another TrxG protein; Acf and both the guide sequences successfully integrated into the pAc-sgRNA-cas9-puro-vector to form two CRISPR-cas9 constructs for Acf gene. For PcG proteins, Pc and Psc, two guide sequences for each Pc1 and Pc2, and Psc8 and Psc9 were synthesized, respectively. Among Pc1 and Pc2, only Pc2 successfully integrated into pAc-sgRNA-cas9-puro-vector to form single-CRISPRcas9 constructs for Pc gene. Both the guide sequences synthesized for Psc gene successfully integrated into pAcsgRNA-cas9-puro-vector to form two CRISPR-cas9 constructs for Psc gene. Finally, in total, we successfully generated eight CRISPR-cas9 constructs, five for TrxG proteins, and three for PcG proteins (Table 1).

\section{Abbreviations \\ CRISPR: Clustered regulatory interspersed short palindromic repeats; DSB: Double-strand break; ISWI: Imitation switch; PCG: Polycomb group; PRC: Polycomb-repressive complex; RNA: Ribonucleic acid; TrxG: Trithorax group \\ Acknowledgements \\ NA \\ Funding \\ NA \\ Availability of data and materials \\ The necessary data was collected during study. However, on request or proposal, additional information will be provided by corresponding author.}

\section{Authors' contributions}

Experimental work was carried out by MAW, while as with data compilation, editing was done by AAG. Both authors read and approved the final manuscript.

Ethics approval and consent to participate NA

Consent for publication

NA.

\section{Competing interests}

The authors declare that they have no competing interests.

\section{Publisher's Note}

Springer Nature remains neutral with regard to jurisdictional claims in published maps and institutional affiliations.

\section{Author details}

${ }^{1}$ Department of Biotechnology, Kashmir University, Srinagar, Jammu \& Kashmir 190001, India. ${ }^{2}$ Environmental Biotechnology Lab, Deptt. of P.G Studies and Research in Biological sciences, R. D. University, Jabalpur 482001, India.

Received: 25 April 2019 Accepted: 4 June 2019

Published online: 04 July 2019

\section{References}

Aliyari R, Ding SW (2009) RNA-based viral immunity initiated by the Dicer family of host immune receptors. Immunol Rev 227(1):176-188

Boboila C, Alt FW, Schwer B (2012) Classical and alternative endjoining pathways for repair of lymphocyte-specific and general DNA doublestrand breaks. Adv Immunol 116:1-49

Deveau H, Barrangou R, Garneau JE, Labonté J, Fremaux C, Boyaval P, Romero DA, Horvath P, Moineau S (2008) Phage response to CRISPR-encoded resistance in Streptococcus thermophilus. J Bacteriol 190(4):1390-1400

Dugar G, Herbig A, Förstner KU, Heidrich N, Reinhardt R, Nieselt K, Sharma CM (2013) High-resolution transcriptome maps reveal strain-specific regulatory features of multiple Campylobacter jejuni isolate. PLoS Genet $9(5): 1-14$

Grissa I, Vergnaud G, Pourcel C (2007) The CRISPRdb database and tools to display CRISPRs and to generate dictionaries of spacers and repeats. BMC Bioinform 8:172

Hatoum-Aslan A, Maniv I, Marraffini LA (2011) Mature clustered, regularly interspaced, short palindromic repeats RNA (crRNA) length is measured by a ruler mechanism anchored at the precursor processing site. Proc Natl Acad Sci U S A 108(52):21218-21222

Horvath P, Romero DA, Coûté-Monvoisin AC, Richards M, Deveau H, Moineau S, Boyaval P, Fremaux C, Barrangou R (2008) Diversity, activity, and evolution of CRISPR loci in Streptococcus thermophilus. J Bacteriol 190(4):1401-1412 
Ingham PW (1998) Trithorax and the regulation of homeotic gene expression in Drosophila: a historical perspective. Int J Dev Biol 42:423-429

Jao LE, Wente SR, Chen W (2013) Efficient multiplex biallelic zebrafish genome editing using a CRISPR nuclease system. Proc Natl Acad Sci U S A 110:13904-13909

Jinek M, Chylinski K, Fonfara I, Hauer M, Doudna JA, Charpentier E (2012) A programmable dual-RNA-guided DNA endonuclease in adaptive bacterial immunity. Science 337(6096):816-821

Long C, McAnally JR, Shelton JM, Mireault AA, Bassel-Duby R, Olson EN (2014) Prevention of muscular dystrophy in mice by CRISPR/ Cas9-mediated editing of germline DNA. Science 345:1184-1188

Marraffini LA, Sontheimer EJ (2010) CRISPR interference: RNA-directed adaptive immunity in bacteria and archaea. Nat Rev Genet 11(3):181-190

Pennisi E (2013) The CRISPR craze. News focus. Science 341(6148):833-836

Shah SA, Hansen NR, Garrett RA (2009) Distribution of CRISPR spacer matches in viruses and plasmids of crenarchaealacido thermophiles and implications for their inhibitory mechanism. Biochem Soc Trans 37:23-28

Tyson GW, Banfield JF (2008) Rapidly evolving CRISPRs implicated in acquired resistance of microorganisms to viruses. Environ Microbiol 10(1):200-207

Wang H, Yang H, Shivalila CS, Dawlaty MM, Cheng AW, Zhang F, Jaenisch R (2013) One-step generation of mice carrying mutations in multiple genes by CRISPR/Cas-mediated genome engineering. Cell 153:910-918

Wiedenheft B, Sternberg SH, Doudna JA (2012) RNA-guided genetic silencing systems in bacteria and archaea. Nature 482(7385):331-338

Xue W, Chen S, Yin H, Tammela T, Papagiannakopoulos T, Joshi NS, Cai W, Yang G, Bronson R, Crowley DG et al (2014) CRISPR mediated direct mutation of cancer genes in the mouse liver. Nature 514:380-384

Yang H, Wang H, Shivalila CS, Cheng AW, Shi L, Jaenisch R (2013) One-step generation of mice carrying reporter and conditional alleles by CRISPR/Casmediated genome engineering. Cell 154:1370-1379

Yin H, Xue W, Chen S, Bogorad RL, Benedetti E, Grompe M, Koteliansky V, Sharp PA, Jacks T, Anderson DG (2014) Genome editing with Cas9 in adult mice corrects a disease mutation and phenotype. Nat Biotechnol 32:551-553

\section{Submit your manuscript to a SpringerOpen ${ }^{\circ}$ journal and benefit from:}

- Convenient online submission

- Rigorous peer review

- Open access: articles freely available online

High visibility within the field

- Retaining the copyright to your article

Submit your next manuscript at $\boldsymbol{\nabla}$ springeropen.com 